\title{
Incorporation of Recycled Tire Products in Pavement-Grade Concrete: An Experimental Study
}

\author{
Sayed Mohamad Soleimani *, Abdel Rahman Alaqqad, Adel Jumaah, Naser Mohammad and Alanoud Faheiman \\ Department of Civil Engineering, Australian College of Kuwait, P.O. Box 1411, Safat 13015, Kuwait; \\ a.alaqqad@ack.edu.kw (A.R.A.); $1414700 @$ go.ack.edu.kw (A.J.); n.mohammad@ack.edu.kw (N.M.); \\ a.faheiman@ack.edu.kw (A.F.) \\ * Correspondence: s.soleimani@ack.edu.kw; Tel.: +965-1828225 (ext. 4046)
}

Citation: Soleimani, S.M.; Alaqqad, A.R.; Jumaah, A.; Mohammad, N.; Faheiman, A. Incorporation of Recycled Tire Products in Pavement-Grade Concrete: An Experimental Study. Crystals 2021, 11, 161. https://doi.org/10.3390/ cryst11020161

Academic Editor: Piotr Smarzewski Received: 19 January 2021

Accepted: 3 February 2021

Published: 6 February 202

Publisher's Note: MDPI stays neutra with regard to jurisdictional claims in published maps and institutional affiliations.

Copyright: (c) 2021 by the authors. Licensee MDPI, Basel, Switzerland. This article is an open access article distributed under the terms and conditions of the Creative Commons Attribution (CC BY) license (https:// creativecommons.org/licenses/by/ $4.0 /)$

\begin{abstract}
The phenomenon of dumping used tires in Kuwait has reached critical levels, with a landfill containing millions of tires being formed in a remote area, which is a major environmental hazard. Nowadays, recycled rubber is used as a suitable and useful material in civil engineering applications, particularly in the production of "green concrete". This study aims to see whether recycled tire by-products can be used to make "green concrete" for pavements. Each type of tire by-product was tested individually to examine its properties and effects on a benchmark mix before creating hybrid mixes that contain a combination of the materials. Eleven mixes containing different doses of shredded or crumbed rubber or steel fibers contained within the tires were made to evaluate their impact on the concrete's slump, compressive strength, split tensile strength, and modulus of rupture. Additionally, twelve hybrid concrete mixes containing different doses of various tire by-products were developed. Preliminary results show that the incorporation of rubber products has a reduction on the concrete's properties. The use of replacement materials sourced from recycled tires using the dosages investigated in this study does not detract from the usability of green pavement concrete suited for hot weather. The concrete produced in this study could be evaluated for specific properties relating to its road safety in further studies. Additionally, long-term effects of using the concrete can be studied using finite element analysis.
\end{abstract}

Keywords: green concrete; shredded rubber; crumbed rubber; steel fiber; recycled tire; pavement; waste materials; sustainability

\section{Introduction}

The management of used tires in Kuwait is considered as a significant environmental challenge [1]. Millions of used tires are dumped to open landfill in Kuwait, although the storage of this type of waste could be a major environmental hazard [2]. As the temperature in Kuwait commonly exceeds $50{ }^{\circ} \mathrm{C}$ during the summer, several massive fires previously destroyed the waste tires, causing serious environmental issues [3-6]. Additionally, the disposal of waste tires in general represents an important environmental concern as the natural degradation of rubber takes several years [7].

Due to an exponential growth in the use of cars in Kuwait, the accumulation of used tires poses a serious risk to the ecosystem; therefore, recycling waste products is vital [8-10]. Recently, great effort has been directed toward finding alternate ways to use waste materials emerging in the world [11-13]. Researchers have found that the recycling of waste rubber tires has several environmental and economic advantages [11,14-16]. Nowadays, the recycled rubber is considered as a suitable and useful material in civil engineering applications $[7,17,18]$. In general, the recycling of the waste tires goes through a process of shredding, separation of components, and granulation in order to convert the tires into ground tire rubber [19].

In most studies, the recycled rubber is classified into three main categories such as shredded rubber (also known as chipped rubber), crumb rubber, and ground rubber [18,20]. 
According to an analytical review done by Lavanga et al., the mechanical response of rubber concrete is affected by different factors such as the rubber content granulometry of both the substituted mineral aggregate (coarse or fine) and the added rubber, the introduction of additives, the quantities of all components within the formulation, the water-to-cement ratio, and the appropriate pre-treatments and surface coatings [13].

A study conducted by Aiello and Leuzzi [21] to investigate the properties of various concrete mixtures concluded that the waste rubber tire can be used toward making workable rubberized concrete. The same study found that the rubberized concrete mixtures showed lower unit weight compared to plain concrete [21]. The literature indicated that the compressive strength of rubberized concrete decreases by increasing the particle size and rubber content $[11,17,18,22]$. Moreover, several studies established an improvement in compressive and tensile strengths in the mixture containing coated rubber crumb and silica fume [23-25].

Meddah et al. [2] recognized that adding shredded rubber can improve the performance of concrete by modifying the roughness of rubber particle surfaces. In addition, the same study pointed that using rubber particles showed improvement in some characteristics such as porosity, ductility, and cracking resistance performance.

Khan and Singh [26] investigated the partial replacement of sand by tire crumb rubber with $5 \%, 10 \%$, and 15\% replacement. The compressive and tensile strengths of the rubberized concrete were reduced by $15 \%$ and $43 \%$ respectively.

Sofi [27] tested high-strength concrete specimens by replacing 5\%,7.5\%, and 10\% of aggregate with rubber and reported a reduction of $10-23 \%$ in the compressive strength. The same study showed that the modulus of elasticity of the rubberized concrete was reduced by $17-25 \%$ and recommended a maximum replacement of $12.5 \%$ of fine aggregate by rubber for high strength concrete.

Akinwonmi and Seckley [28] investigated the change in compressive strength of concrete when the aggregates were replaced with shredded and crumb rubber. The results showed that the replacement of $2.5 \%$ shredded rubber increased the compressive strength by $8.5 \%$, while any replacement of more than $2.5 \%$ rubber decreased the compressive strength when compared to the control mix.

Issa and Salem [29] reported that partial replacement of the sand with crumb rubber up to $25 \%$ would result in an acceptable compressive strength for the concrete. He indicated that increasing the rubber content above this threshold would reduce the compressive strength substantially that the mix would not be acceptable for structural or even nonstructural applications.

Recently, Irmawaty et al. [30] investigated the flexural behavior of the concrete made in part by using waste rubber tires. They tested specimens with $100 \mathrm{~mm} \times 100 \mathrm{~mm} \times 400 \mathrm{~mm}$ and with the replacement of $10 \%, 20 \%$, and $30 \%$ of crumb rubber and tire chips. They concluded that rubberized concrete with $10 \%$ crumb rubber achieved the optimal energy absorption.

The literature made it clear that the greater the amount of steel fibers in the concrete, the greater the value of strength and flexural toughness [31-34]. Therefore, the addition of steel fiber appears to improve the tensile and compressive strengths [32,34,35].

Gul and Nasser [32] conducted a study to investigate the behavior of concrete by using the waste rubber tires as an alternative to steel fiber in fiber-reinforced concrete. They concluded that by increasing the percentage replacement of rubber, the compressive and split tensile strengths of concrete decrease compared to specimens containing steel fiber.

Manufactured steel fibers and steel fibers extracted from tire waste have been used in different concrete mixes to compare their effectiveness [33]. The increase in both reused and normal steel fibers showed less slump values for fresh concrete. The initial modulus of elasticity increased by $7-8 \%$ for the mixes with normal steel fibers and $2-3 \%$ for the mixes with reused steel fibers. The compressive strength of the mix with reused fibers increased by a maximum of $12 \%$, while the mix with normal fibers increased by a maximum of $20 \%$. 
No significant increase was noticed in the splitting tensile strength test between the two mixes while increasing the fiber dosage.

Some researchers examined the hybrid concrete mixes: for example, Noaman et al. [34] investigated the mechanical properties of rubberized concrete combined with steel fiber. They combined rubberized concrete with different replacement ratios of crumb rubber in plain and steel fiber concrete mixes via the partial replacement of fine aggregate $(17.5 \%$, $20 \%, 22.5 \%$, and $25 \%$ ). The study indicated that a reduction in mechanical properties was observed by the increasing increment of crumb rubber in both mixes. The study suggested using a combination of steel fiber and crumb rubber due to the improvement of strain capacity under flexural loading.

As well, Eisa et al. [35] studied the effect of a combination of crumb rubber and steel fibers on the behavior of reinforced concrete beams under static loads. They concluded that an acceptable level of performance of reinforced concrete beams could be obtained by using crumb rubber as a partial replacement of fine aggregates by $5 \%$ and $10 \%$. The study also recommended the use of steel fibers with rubberized concrete, with percentages of rubber over $10 \%$, as this showed a significant improvement in the performance and toughness of these mixtures.

As per the above literature review, researchers directed great attention to investigating the utilization of recycled tire rubber in concrete in order to find a proper solution for minimizing tire waste and producing a green concrete. In spite of the reduction in mechanical properties due to increasing the rubber content in the mix $[11,13,17,18,22,31]$, it is still recommended to use rubber particles in civil engineering applications, especially in pavement projects $[2,11,15,17,20,35,36]$.

The objective of this study is to investigate whether recycled tire by-products can be used to make a suitable "green concrete" to be used for pavement construction in hot-weather climates. To achieve optimal results, each type of tire by-product was tested individually to observe its properties and effects on a benchmark mix before creating "hybrid" mixes that contain a combination of the materials; this is where the novelty of this study lies.

\section{Materials and Methods}

\subsection{Benchmark Concrete Mix Design}

In this study, a benchmark pavement-grade concrete mix with a 28-day compressive strength of about $35 \mathrm{MPa}$ has been designed and cast. Concrete pavements are preferred in Kuwait due to their ability to resist high temperatures without causing permanent damage to the pavement itself. However, concrete used in hot climates is subjected to high rates of evaporation, loss of moisture, and quick setting times [37]. As a result, concrete mixes used in hot weather climates need to have a slump value at the higher end of the recommended range for pavements. This was achieved by introducing a superplasticizer in order to improve the workability of the mix and reach the targeted 28-day compressive strength while limiting the water/cement ratio to 0.55 . The mix proportions of the benchmark concrete used for the study are shown in Table 1.

Table 1. Mix design propositions of benchmark pavement-grade concrete.

\begin{tabular}{cc}
\hline Material & Quantity \\
\hline Cement $\left(\mathrm{kg} / \mathrm{m}^{3}\right)$ & 327 \\
Sand $\left(\mathrm{kg} / \mathrm{m}^{3}\right)$ & 663 \\
Coarse aggregates: $9.5 \mathrm{~mm}\left(\mathrm{~kg} / \mathrm{m}^{3}\right)$ & 740 \\
Coarse aggregates: $12.5 \mathrm{~mm}\left(\mathrm{~kg} / \mathrm{m}^{3}\right)$ & 442 \\
Water $\left(\mathrm{kg} / \mathrm{m}^{3}\right)$ & 180 \\
SIKAment ${ }^{\circledR}-500$ OM Superplasticizer $(\%$ of binder weight $)$ & 2.00 \\
Water/Cement ratio & 0.55 \\
\hline
\end{tabular}


To achieve the desired workability, SIKAment ${ }^{\circledR}-500$ OM superplasticizer is used. This is important for hot climate places.

\subsection{Recycled Tire Products}

Crumb rubber (CR), shredded rubber (SR), and steel fibers (SF) were obtained by recycling used tires (Figure 1). These products are easily available in the market, as tires are now recycled around the world. The tire rubber used in this study is varied in source but is believed to contain percentages of natural and synthetic hydrophobic rubber optimized for automobile use. For this study, the recycled tire products were provided by the Green Rubber Tire Recycling Plant in Kuwait.

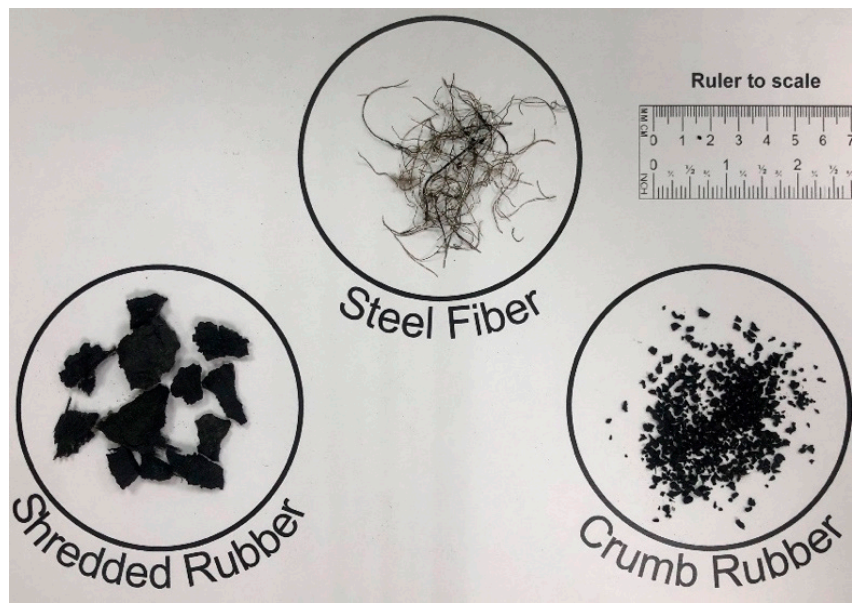

Figure 1. Crumb rubber, shredded rubber, and steel fibers obtained by recycling used tires.

$\mathrm{CR}$ and SR are used as a partial replacement for the sand and coarse aggregates respectively. SF is used as an extra ingredient in different concrete mixes.

\subsubsection{Crumb Rubber (CR)}

The density of CR used in this study is $552 \mathrm{~kg} / \mathrm{m}^{3}$. The size distribution, by sieve analysis, is shown in Figure 2 and is compared with the size distribution of the sand used in this project. The particle size distribution of the sand is close to being well-graded, whereas the $C R$ is uniformly graded. Ideally, the CR would be introduced to replace a similarly sized portion of the sand; however, this is not feasible in real-life applications. Therefore, a direct replacement of sand with $C R$ is used.

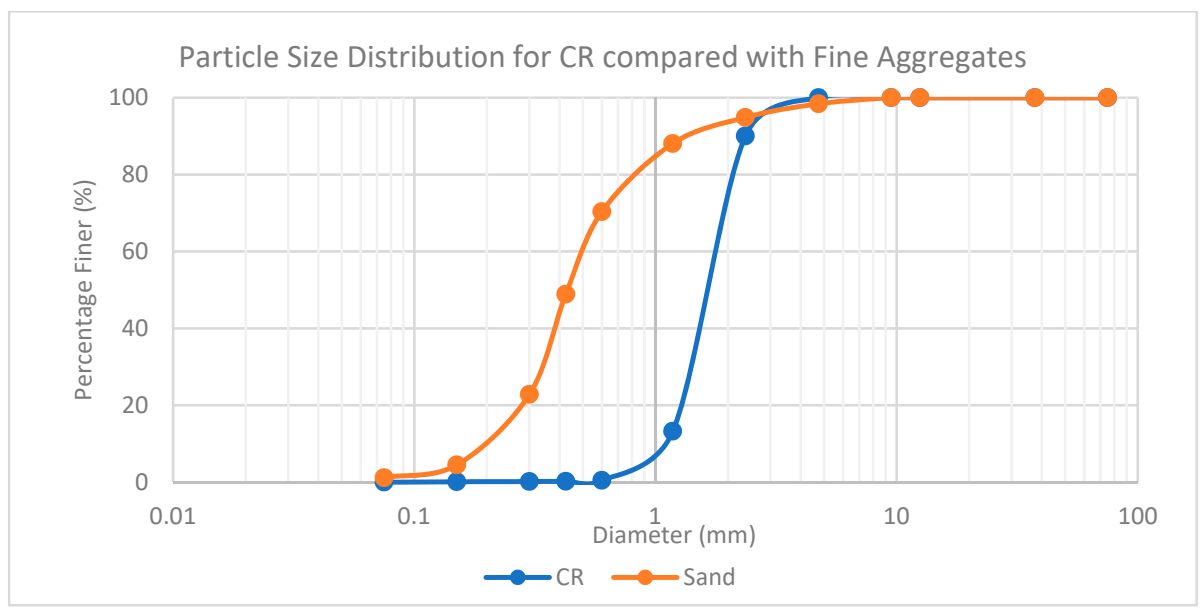

Figure 2. Size distribution of crumb rubber and sand used in this study. 


\subsubsection{Shredded Rubber (SR)}

The density of SR used in this study is $566 \mathrm{~kg} / \mathrm{m}^{3}$. SR obtained from the recycling plant has been sieved, and particles smaller than $12.5 \mathrm{~mm}$ are used to make sure that similarly-sized SR particles are used in the partial replacement of the coarse aggregates. The size distribution of the SR, which is also compared with that of the coarse aggregates $(9.5 \mathrm{~mm}$ and $12.5 \mathrm{~mm})$, is shown in Figure 3. The particle size distribution for both sizes of coarse aggregate as well as the SR are more or less well-distributed, and interestingly, the particle size distribution of the SR fits in between the two sizes of coarse aggregates used in this study. Therefore, a direct replacement of both sizes of coarse aggregates with SR is used.

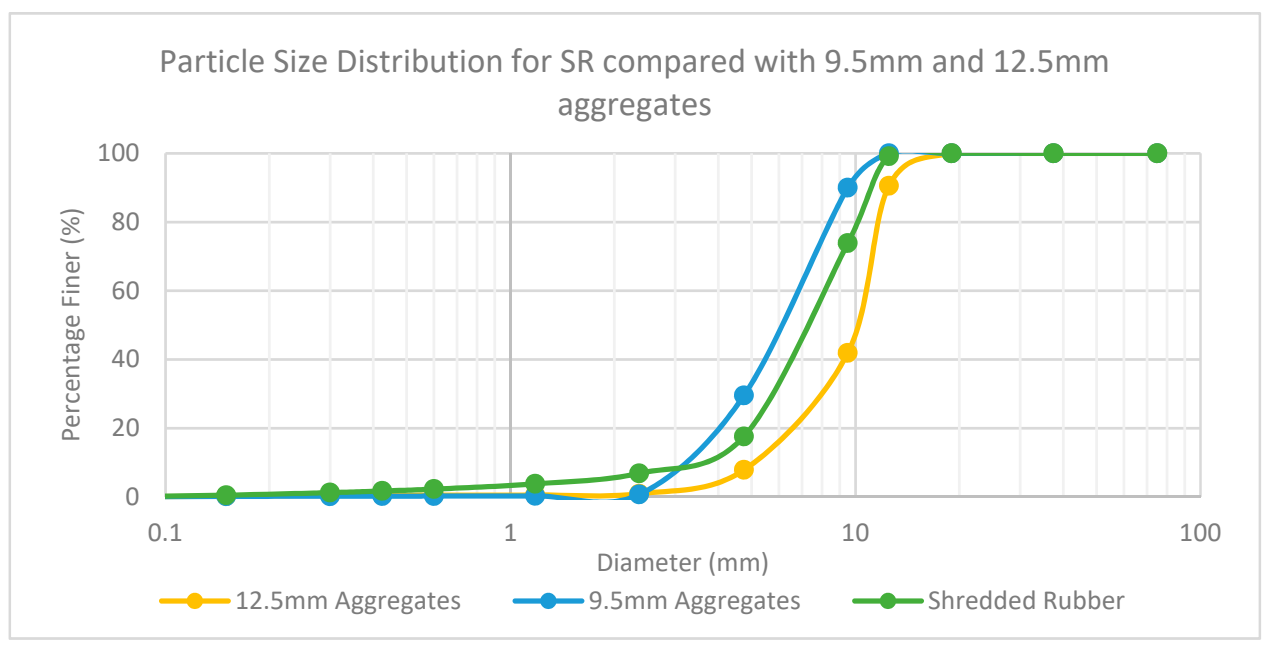

Figure 3. Size distribution of shredded rubber and coarse aggregates used in this study.

\subsubsection{Steel Fibers (SF)}

The density of SR used in this study is $7850 \mathrm{~kg} / \mathrm{m}^{3}$. The length and diameter of $100 \mathrm{ran}-$ domly selected steel fibers have been measured, and the results are shown in Table 2.

Table 2. Steel fibers dimensions.

\begin{tabular}{ccc}
\hline Dimension & Average & Standard Deviation \\
\hline Length $(\mathrm{mm})$ & 24 & 8.6 \\
Diameter $(\mathrm{mm})$ & 0.34 & 0.076 \\
\hline
\end{tabular}

\subsection{Concrete Mixes Containing Recycled Tire Products}

A total of 24 concrete mixes are cast, including the benchmark. The mix codes and descriptions are shown in Table 3. SR, CR, and SF in the concrete mix codes show the presence of shredded rubber, crumb rubber, and steel fiber in the concrete mix respectively. When combinations of SF, CR, and SF are used in a concrete mix, the code starts with an "H."

For each concrete mix, a total of 14 cylinders (100 mm diameter by $200 \mathrm{~mm}$ height) and 3 beams $(100 \mathrm{~mm} \times 100 \mathrm{~mm} \times 400 \mathrm{~mm})$ are cast and sulfur-capped as per ASTM C617 [38]. A minimum of 3 cylinders are tested to calculate the tensile strength at 28 days as per ASTM C496 [39]. Similarly, a minimum of 3 cylinders are used to calculate the compressive strength at 7 and 28 days (Figure 4) as per ASTM C39 [40]. For the benchmark concrete only, 3 cylinders are tested at 3 days under compression. 
Table 3. Concrete mixes and descriptions.

\begin{tabular}{|c|c|c|}
\hline No. & Code & Description \\
\hline 1 & $\mathrm{BM}$ & Benchmark concrete with no recycled tire products \\
\hline 2 & SR-1 & $\begin{array}{c}5 \% \text { (by volume) of coarse aggregates }(9.5 \text { and } 12.5 \mathrm{~mm}) \text { is replaced by } \\
\text { shredded rubber }\end{array}$ \\
\hline 3 & SR-2 & $\begin{array}{c}10 \% \text { (by volume) of coarse aggregates }(9.5 \text { and } 12.5 \mathrm{~mm} \text { ) is replaced by } \\
\text { shredded rubber }\end{array}$ \\
\hline 4 & SR-3 & $\begin{array}{l}15 \% \text { (by volume) of coarse aggregates }(9.5 \text { and } 12.5 \mathrm{~mm} \text { ) is replaced by } \\
\text { shredded rubber }\end{array}$ \\
\hline 5 & SR-4 & $\begin{array}{l}20 \% \text { (by volume) of coarse aggregates }(9.5 \text { and } 12.5 \mathrm{~mm} \text { ) is replaced by } \\
\text { shredded rubber }\end{array}$ \\
\hline 6 & CR-1 & $5 \%$ (by volume) of sand is replaced by crumb rubber \\
\hline 7 & CR-2 & $10 \%$ (by volume) of sand is replaced by crumb rubber \\
\hline 8 & CR-3 & $15 \%$ (by volume) of sand is replaced by crumb rubber \\
\hline 9 & CR-4 & $20 \%$ (by volume) of sand is replaced by crumb rubber \\
\hline 10 & SF-1 & $0.1 \%$ steel fibers are added to BM (by volume of concrete) \\
\hline 11 & SF-2 & $0.2 \%$ steel fibers are added to BM (by volume of concrete) \\
\hline 12 & SF-3 & $0.3 \%$ steel fibers are added to BM (by volume of concrete) \\
\hline 13 & $\mathrm{H}-1$ & $\begin{array}{l}5 \% \text { (by volume) of coarse aggregates ( } 9.5 \text { and } 12.5 \mathrm{~mm} \text { ) is replaced by } \\
\text { shredded rubber and } 0.1 \% \text { steel fibers (by volume of concrete) are added to } \\
\text { the mix }\end{array}$ \\
\hline 14 & $\mathrm{H}-2$ & $\begin{array}{l}10 \% \text { (by volume) of coarse aggregates }(9.5 \text { and } 12.5 \mathrm{~mm} \text { ) is replaced by } \\
\text { shredded rubber and } 0.1 \% \text { steel fibers (by volume of concrete) are added to } \\
\text { the mix }\end{array}$ \\
\hline 15 & H-3 & $\begin{array}{l}15 \% \text { (by volume) of coarse aggregates }(9.5 \text { and } 12.5 \mathrm{~mm} \text { ) is replaced by } \\
\text { shredded rubber and } 0.1 \% \text { steel fibers (by volume of concrete) are added to } \\
\text { the mix }\end{array}$ \\
\hline 16 & $\mathrm{H}-4$ & $\begin{array}{l}20 \% \text { (by volume) of coarse aggregates ( } 9.5 \text { and } 12.5 \mathrm{~mm} \text { ) is replaced by } \\
\text { shredded rubber and } 0.1 \% \text { steel fibers (by volume of concrete) are added to } \\
\text { the mix }\end{array}$ \\
\hline 17 & H-5 & $\begin{array}{l}5 \% \text { (by volume) of sand is replaced by crumb rubber and } 0.1 \% \text { steel fibers } \\
\text { (by volume of concrete) are added to the mix }\end{array}$ \\
\hline 18 & H-6 & $\begin{array}{c}10 \% \text { (by volume) of sand is replaced by crumb rubber and } 0.1 \% \text { steel fibers } \\
\text { (by volume of concrete) are added to the mix }\end{array}$ \\
\hline 19 & $\mathrm{H}-7$ & $\begin{array}{l}15 \% \text { (by volume) of sand is replaced by crumb rubber and } 0.1 \% \text { steel fibers } \\
\text { (by volume of concrete) are added to the mix }\end{array}$ \\
\hline 20 & $\mathrm{H}-8$ & $\begin{array}{c}20 \% \text { (by volume) of sand is replaced by crumb rubber and } 0.1 \% \text { steel fibers } \\
\text { (by volume of concrete) are added to the mix }\end{array}$ \\
\hline 21 & H-9 & $\begin{array}{l}5 \% \text { (by volume) of coarse aggregates ( } 9.5 \text { and } 12.5 \mathrm{~mm} \text { ) is replaced by } \\
\text { shredded rubber, } 5 \% \text { (by volume) of sand is replaced by crumb rubber, and } \\
0.1 \% \text { steel fibers (by volume of concrete) are added to the mix }\end{array}$ \\
\hline 22 & $\mathrm{H}-10$ & $\begin{array}{l}10 \% \text { (by volume) of coarse aggregates ( } 9.5 \text { and } 12.5 \mathrm{~mm} \text { ) is replaced by } \\
\text { shredded rubber, } 10 \% \text { (by volume) of sand is replaced by crumb rubber, } \\
\text { and } 0.1 \% \text { steel fibers (by volume of concrete) are added to the mix }\end{array}$ \\
\hline 23 & $\mathrm{H}-11$ & $\begin{array}{l}5 \% \text { (by volume) of coarse aggregates ( } 9.5 \text { and } 12.5 \mathrm{~mm} \text { ) is replaced by } \\
\text { shredded rubber and } 5 \% \text { (by volume) of sand is replaced by crumb rubber }\end{array}$ \\
\hline 24 & H-12 & $\begin{array}{l}10 \% \text { (by volume) of coarse aggregates ( } 9.5 \text { and } 12.5 \mathrm{~mm} \text { ) is replaced by } \\
\text { shredded rubber and } 10 \% \text { (by volume) of sand is replaced by crumb rubber }\end{array}$ \\
\hline
\end{tabular}




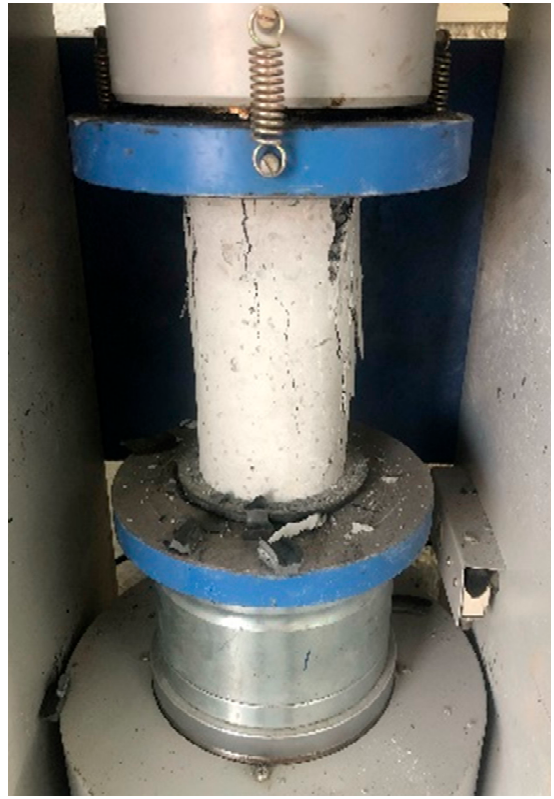

(a)

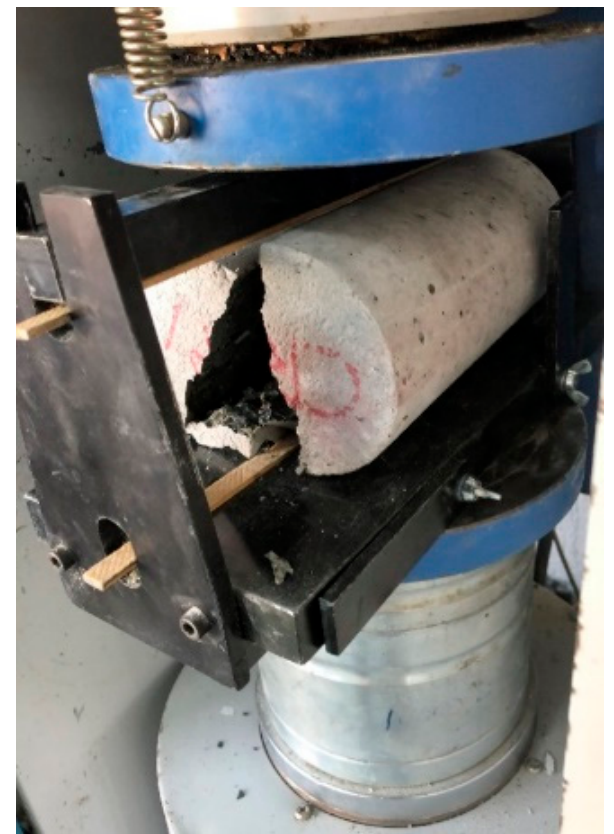

(b)

Figure 4. Test of a concrete cylindrical sample (a) Compression; and (b) Tension.

Third-point loading tests (Figure 5) are performed on the beams to obtain the modulus of rupture of the concrete mix as per ASTM C78 [41].

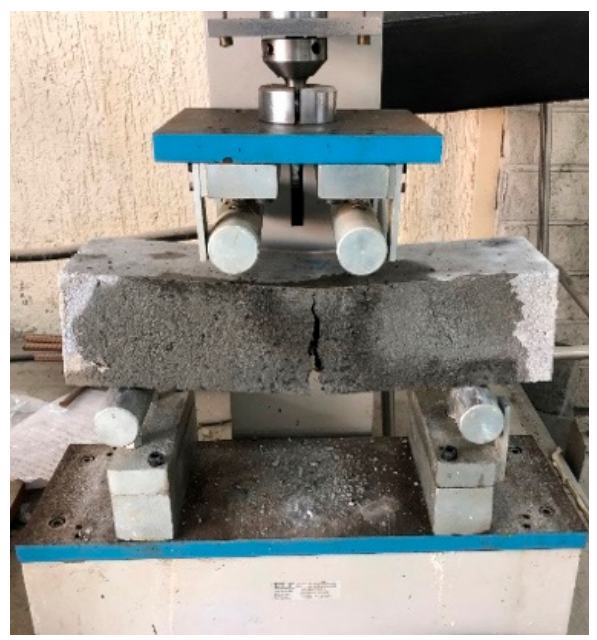

Figure 5. Third-point loading test to obtain the modulus of rupture.

\section{Results}

\subsection{Slump Test Results}

For a pavement-grade concrete mix in a hot climate, a target slump of $70 \mathrm{~mm} \pm 30 \mathrm{~mm}$ is set. The slump of the benchmark concrete, BM, was $75 \mathrm{~mm}$, and the slump of all other concrete mixes were within the targeted range. The slump test results are compared in Figure 6. It is worth mentioning that in all mixes, oven-dried sand and aggregates are used to ensure consistency in water-to-cement ratio. In addition, to improve the workability of concrete mixes, superplasticizer is used in all mixes ( $2.0 \%$ to $2.5 \%$ of the weight of cement). Since $2.0 \%$ is used for the benchmark, a minimum amount of $2.0 \%$ is used in all other mixes; if the workability is not desirable, an extra $0.5 \%$ is added to the mix. 


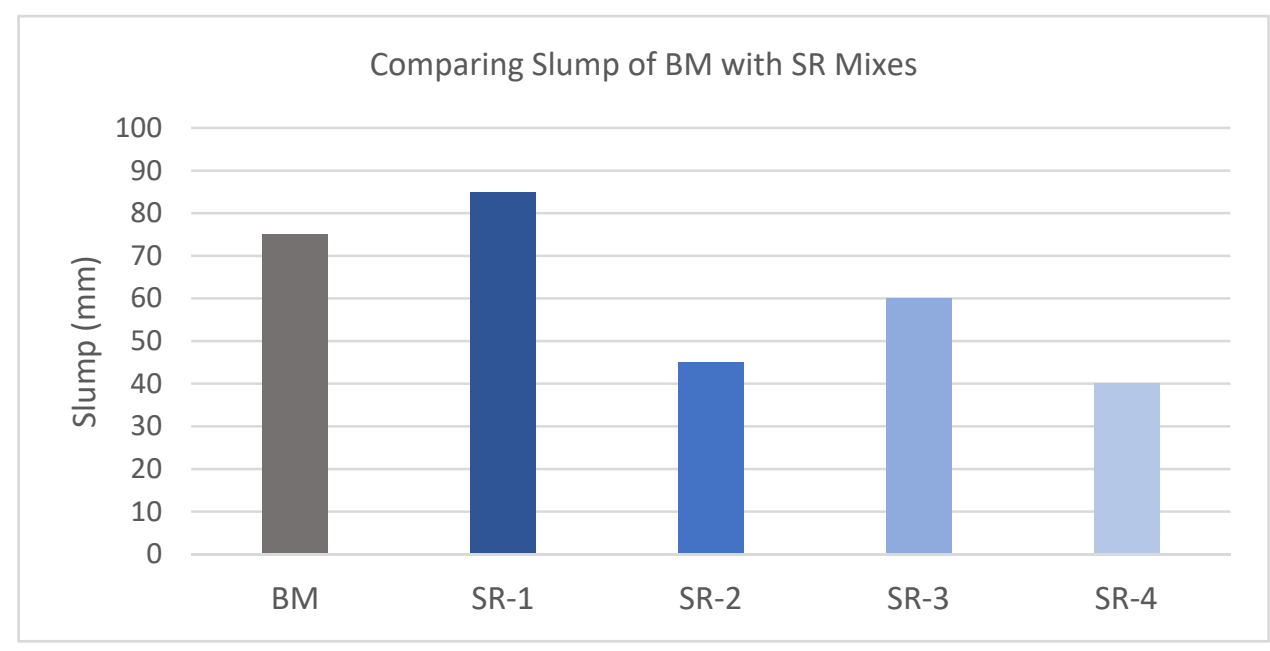

(a)

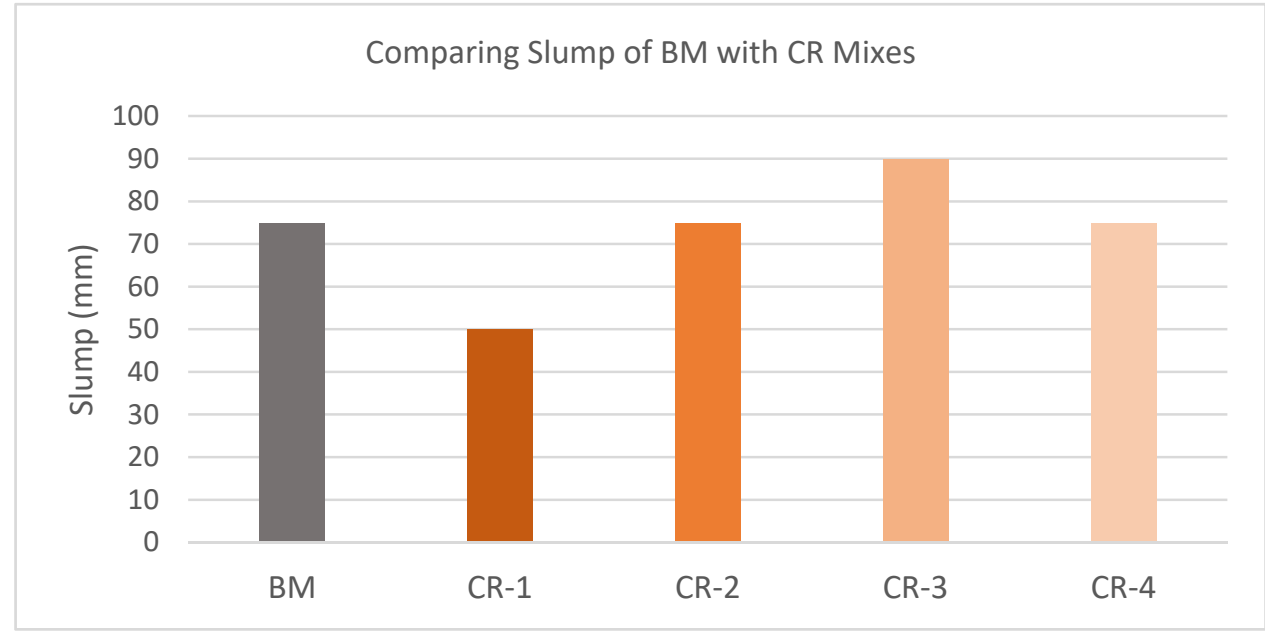

(b)

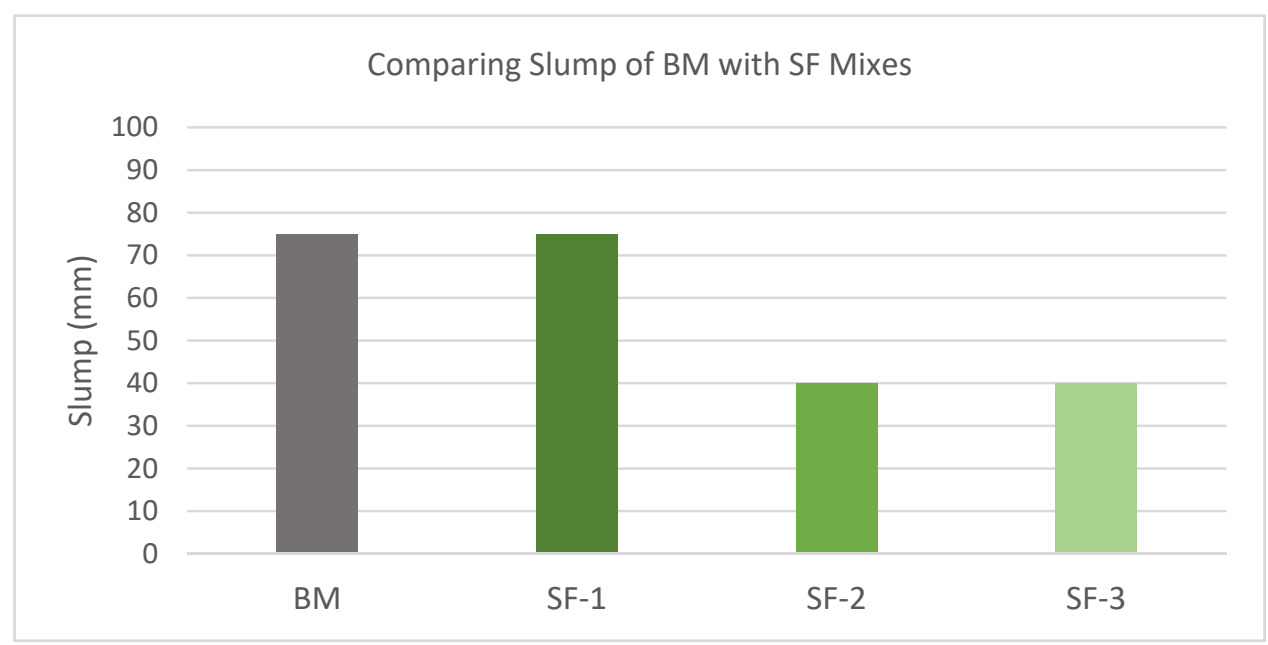

(c)

Figure 6. Cont. 


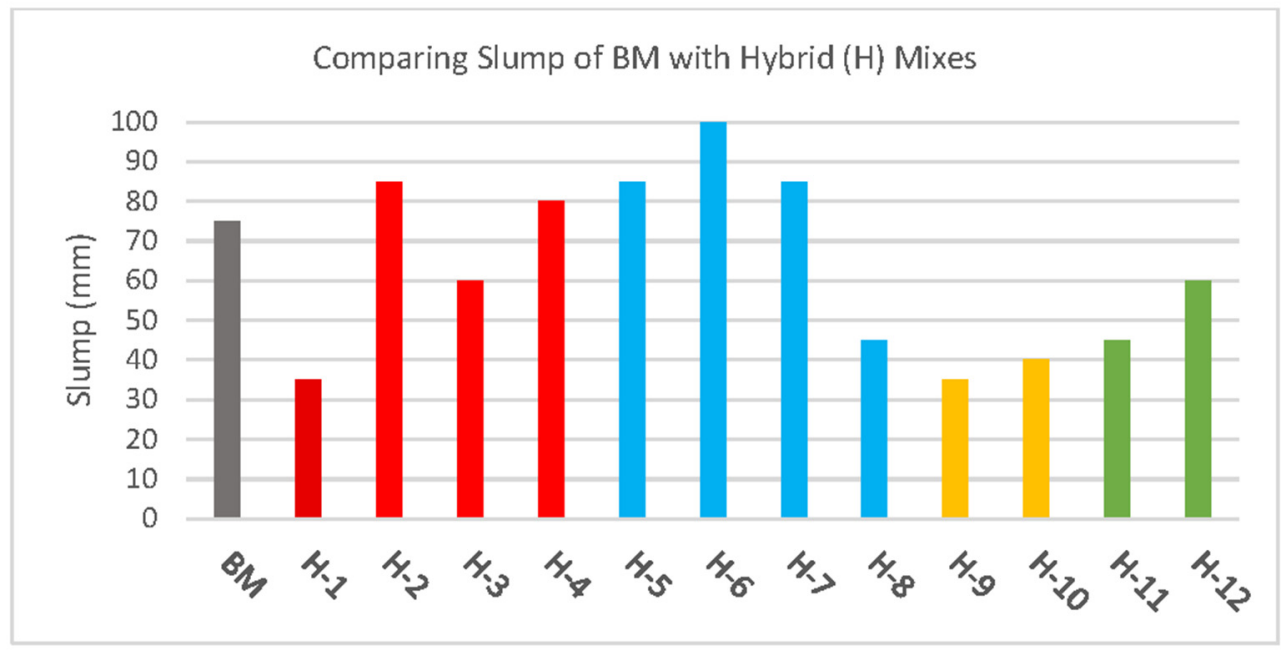

(d)

Figure 6. Comparing the slump test results of benchmark $(75 \mathrm{~mm})$ with (a) shredded rubber (SR); (b) crumb rubber (CR); (c) steel fibers (SF); and (d) Hybrid (i.e., H) mixes.

\subsection{Density of Concrete}

The BM's density is $2390 \mathrm{~kg} / \mathrm{m}^{3}$. Replacing the coarse aggregates and sand by SR and CR respectively reduces the density. For example, the density of SR-4 and CR-4 is $2317 \mathrm{~kg} / \mathrm{m}^{3}$ and $2362 \mathrm{~kg} / \mathrm{m}^{3}$, respectively. On the other hand, the addition of SF increases the density; for example, SF-3 has a density of $2425 \mathrm{~kg} / \mathrm{m}^{3}$. In the hybrid mixes (i.e., H-1 to $\mathrm{H}-12)$, the maximum density is seen in $\mathrm{H}-5\left(2402 \mathrm{~kg} / \mathrm{m}^{3}\right)$ and the minimum is seen in H-4 $\left(2314 \mathrm{~kg} / \mathrm{m}^{3}\right)$.

\subsection{Compressive Strength}

A minimum of 3 cylinders are tested in order to obtain the compressive strength. Figure 7 shows the compressive strength of BM mix at 3, 7, and 28 days. All other mixes are tested at 7 and 28 days. The compressive strength of SR, CR, and SF mixes at these two ages are compared with those of the BM mix in Figure 8. Similarly, the compressive strength of hybrid mixes (H-1 to H-12) are compared with BM in Figure 9.

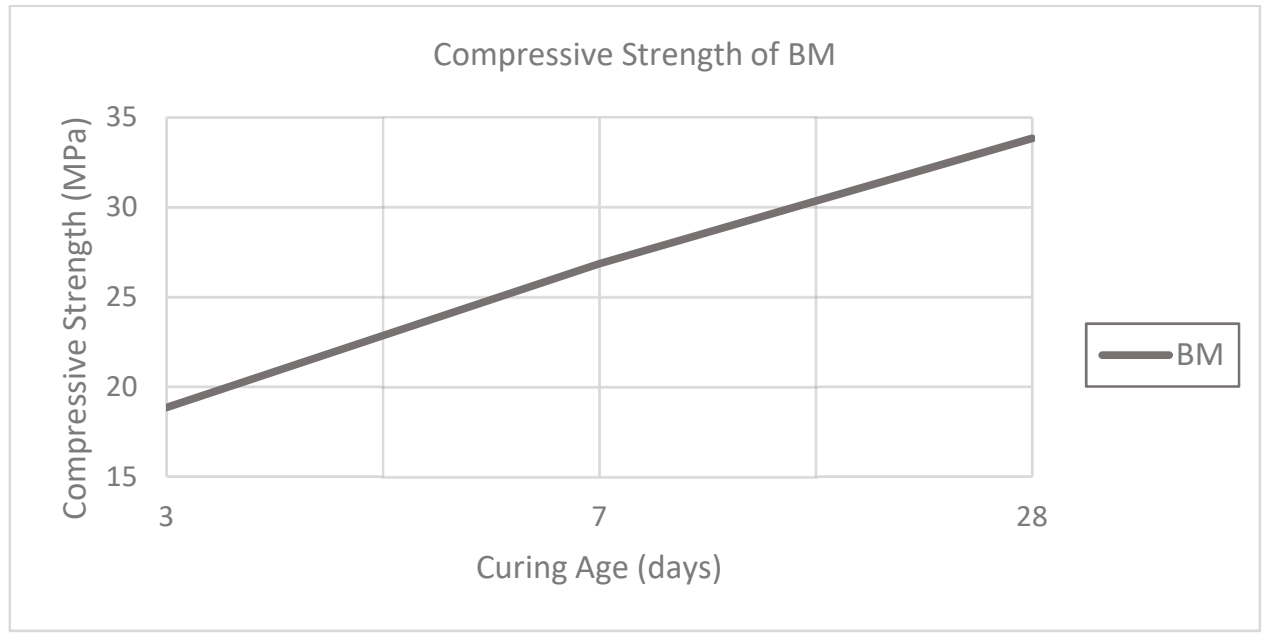

Figure 7. Compressive strength of the benchmark mix at 3, 7, and 28 days. 


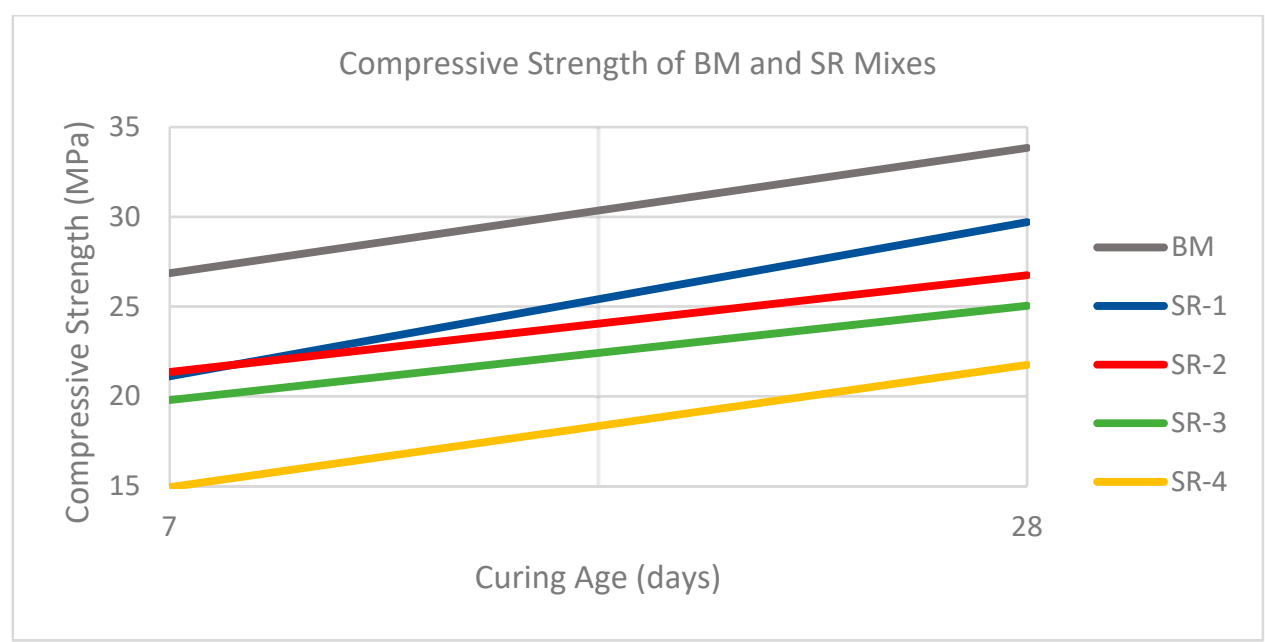

(a)

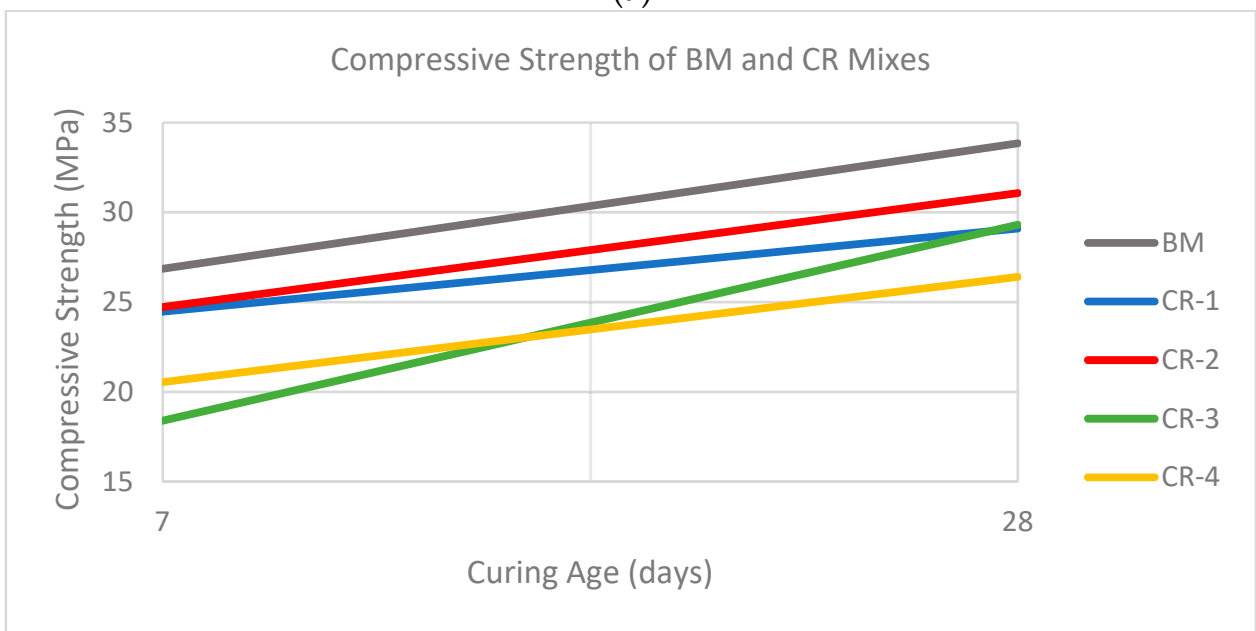

(b)

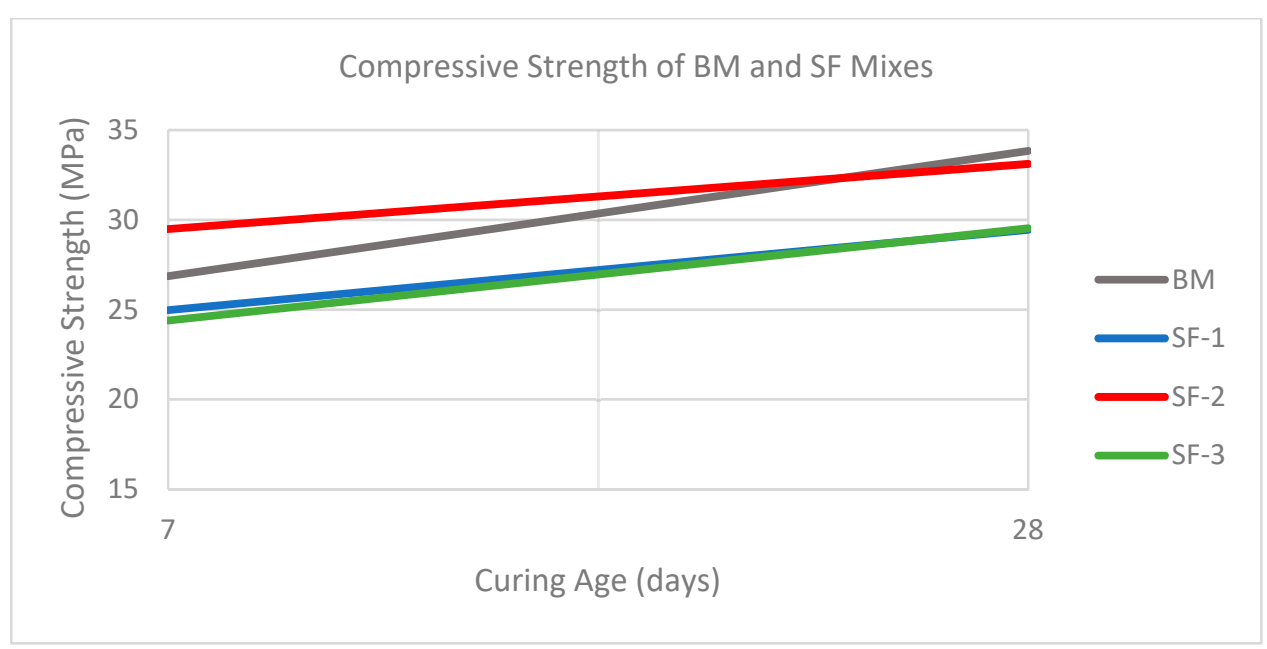

(c)

Figure 8. Comparing the compressive strength of the benchmark mix with (a) SR; (b) CR; and (c) SF mixes. 


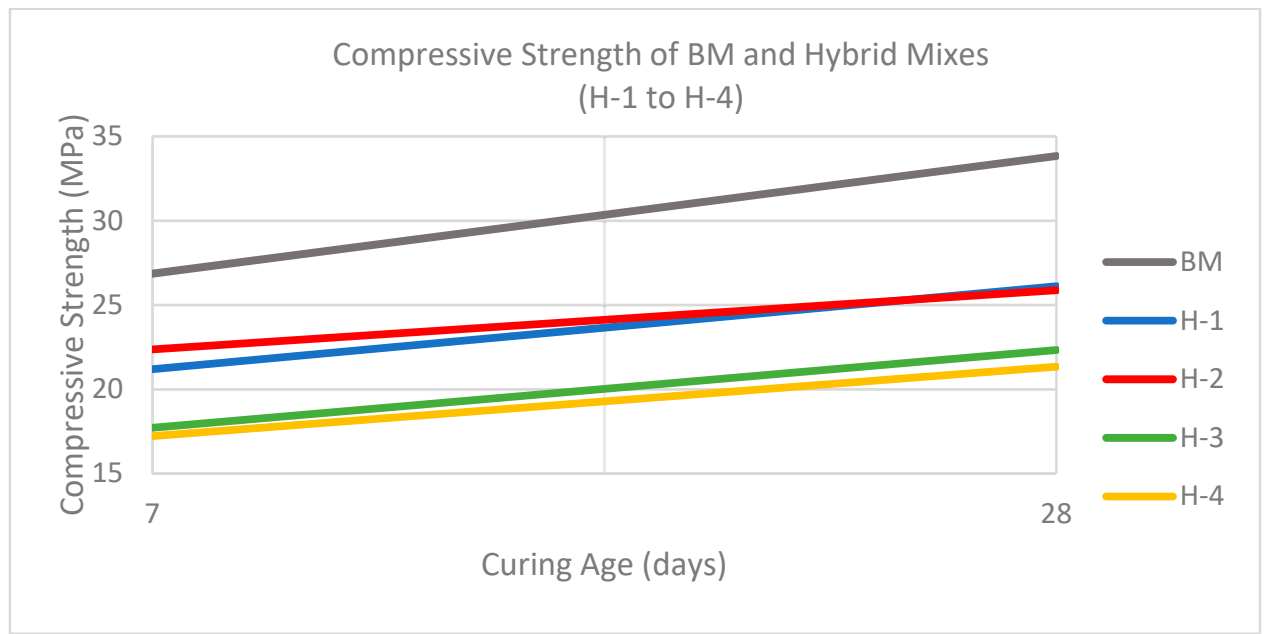

(a)

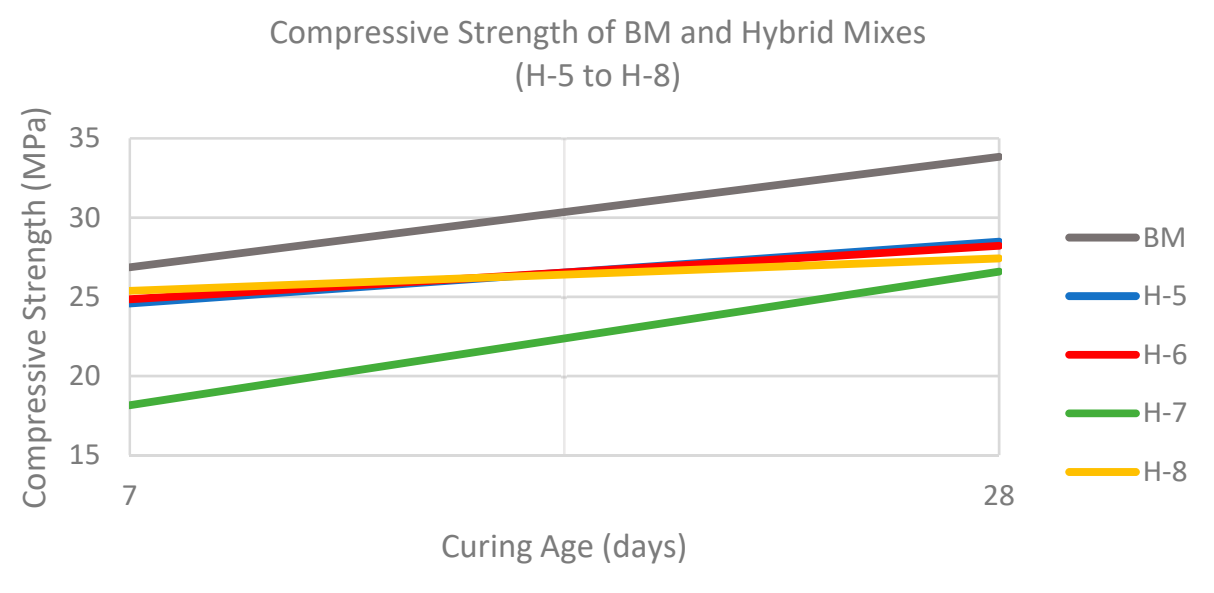

(b)

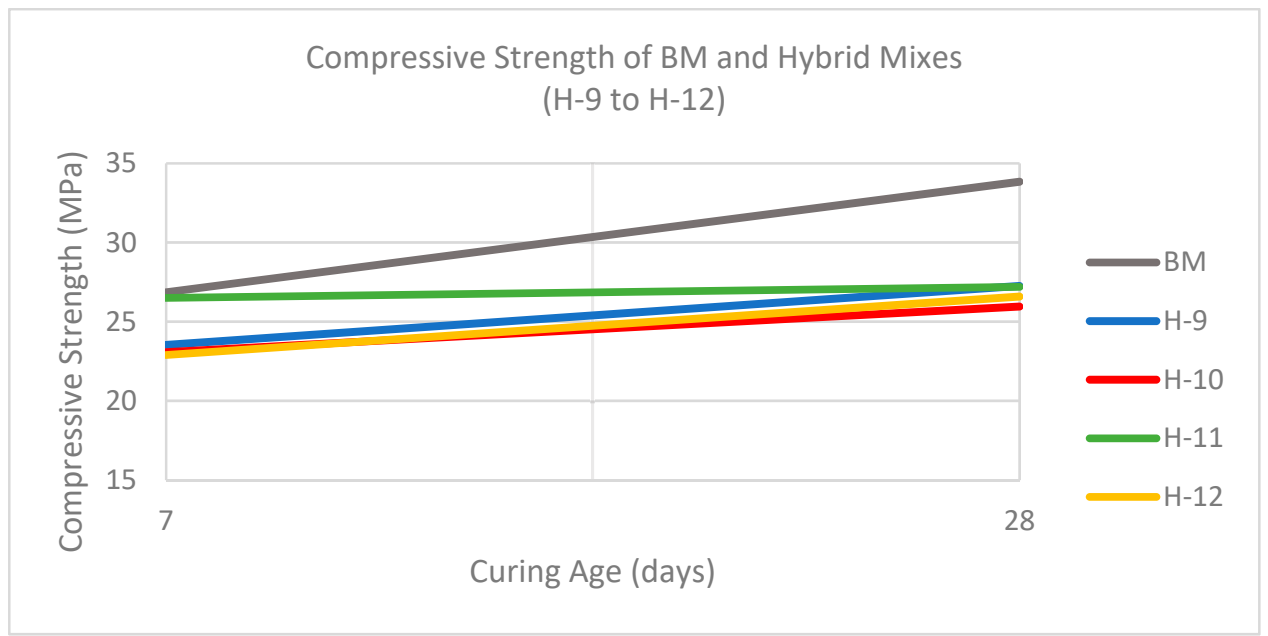

(c)

Figure 9. Comparing the compressive strength of the benchmark mix with hybrid mixes (a) $\mathrm{H}-1$ to H-4; (b) H-5 to H-8; and (c) H-9 to H-12.

\subsection{Tensile Strength}

A splitting tensile test is performed on 3 cylinders for each mix, and the average tensile strength of the benchmark mix is compared with that of all other mixes in Figure 10. 


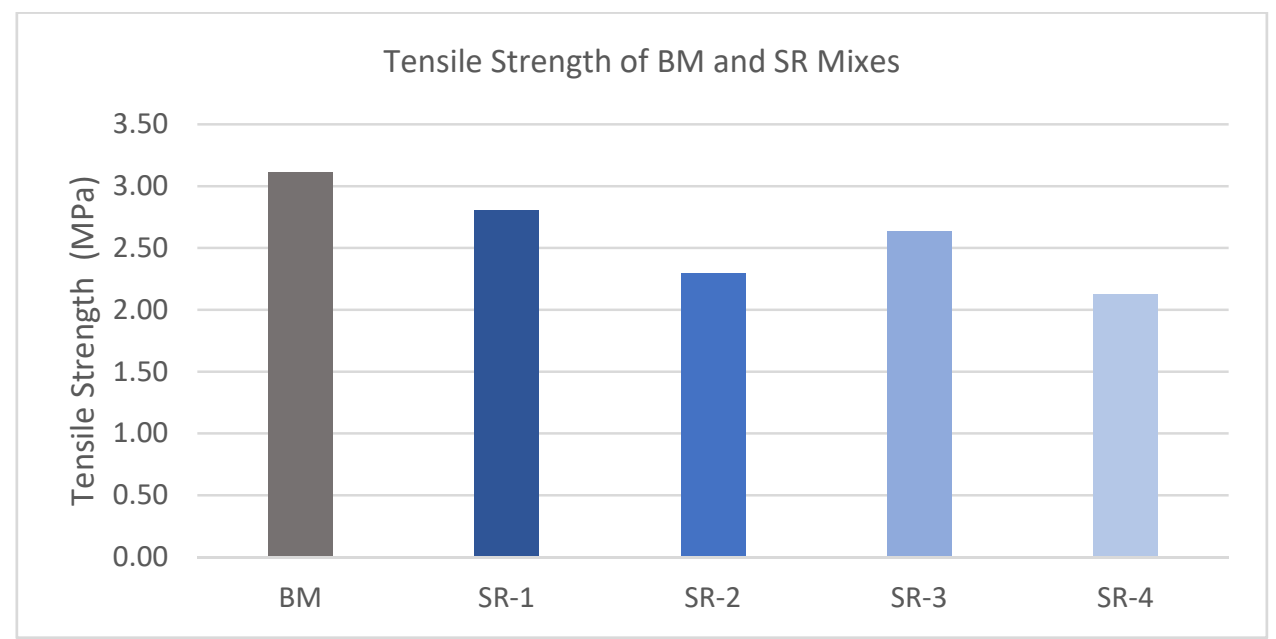

(a)

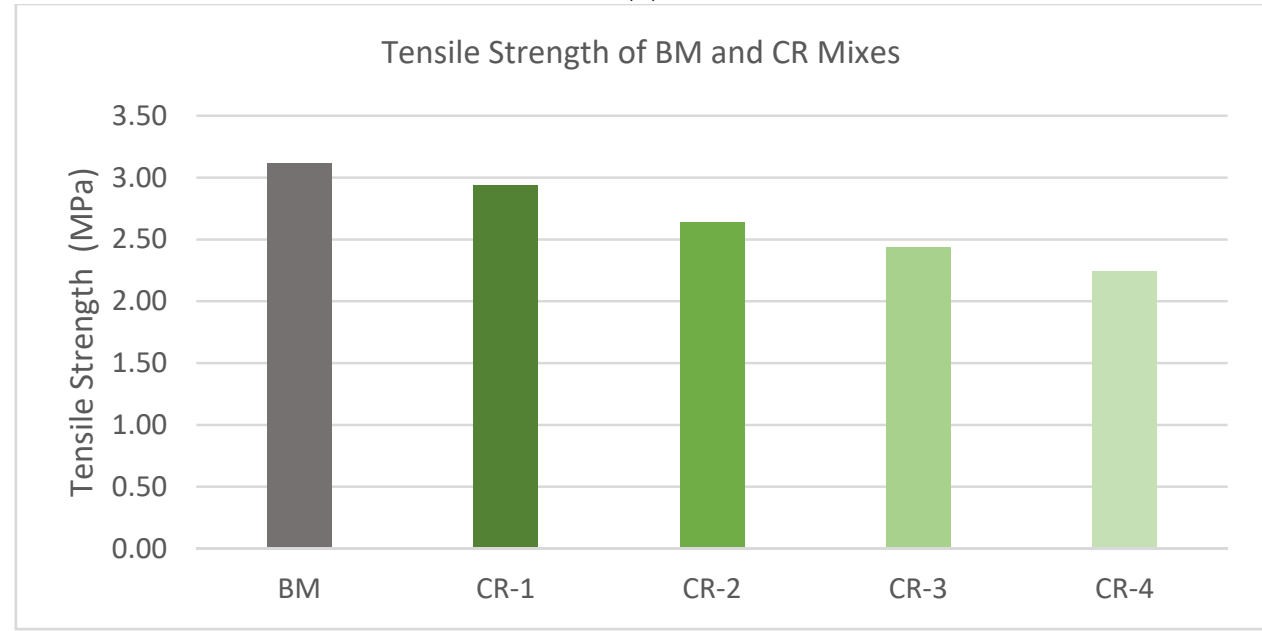

(b)

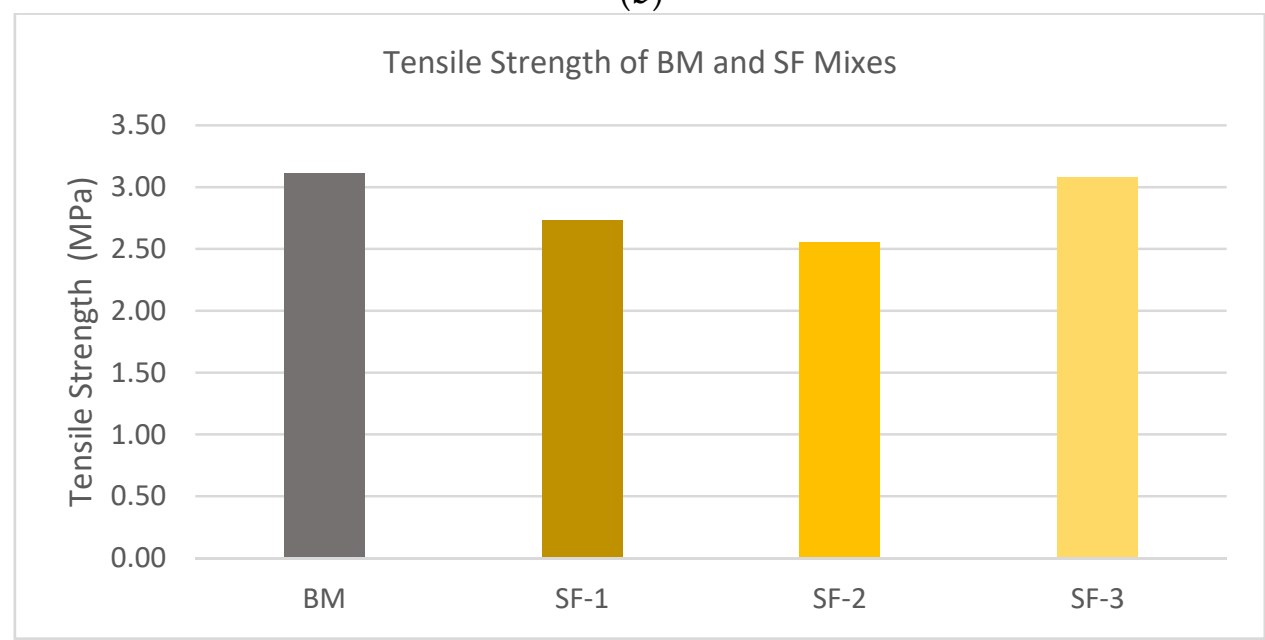

(c)

Figure 10. Cont. 


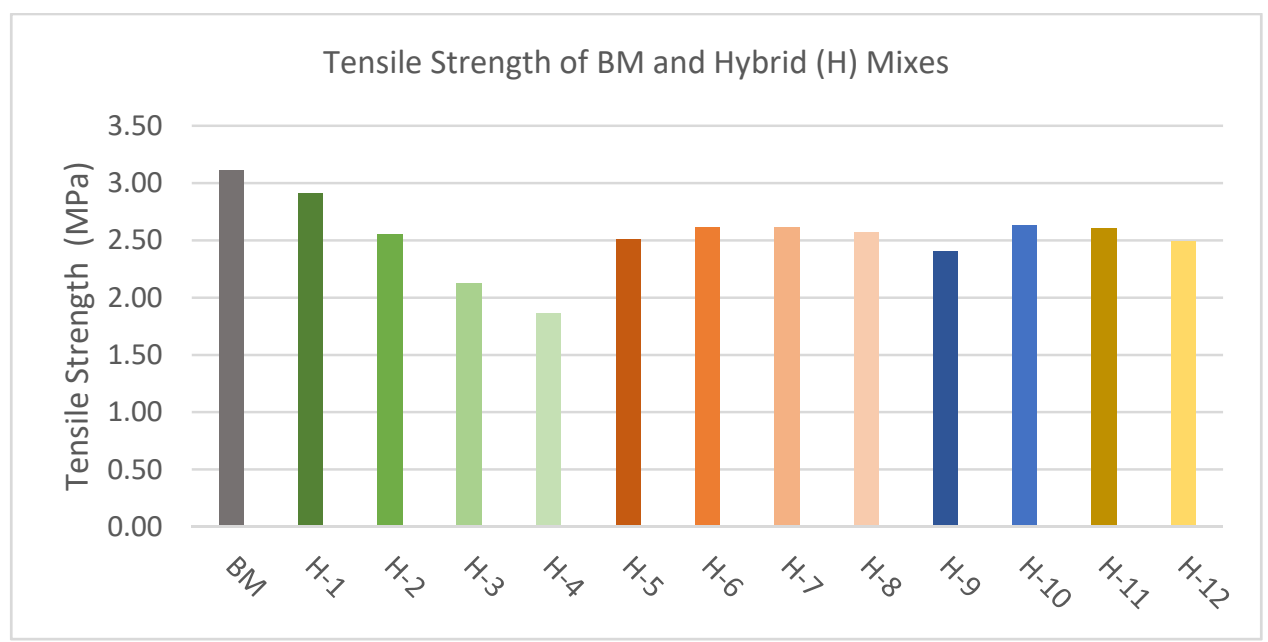

(d)

Figure 10. Comparing the tensile strength of the benchmark mix (3.11 MPa) with (a) SR; (b) CR; (c) SF; and (d) Hybrid (i.e., H) mixes.

\subsection{Modulus of Rupture}

A third-point loading test is performed on 3 beams for each mix, and the average value relating to the modulus of rupture of the benchmark mix is compared with that of all other mixes in Figure 11.

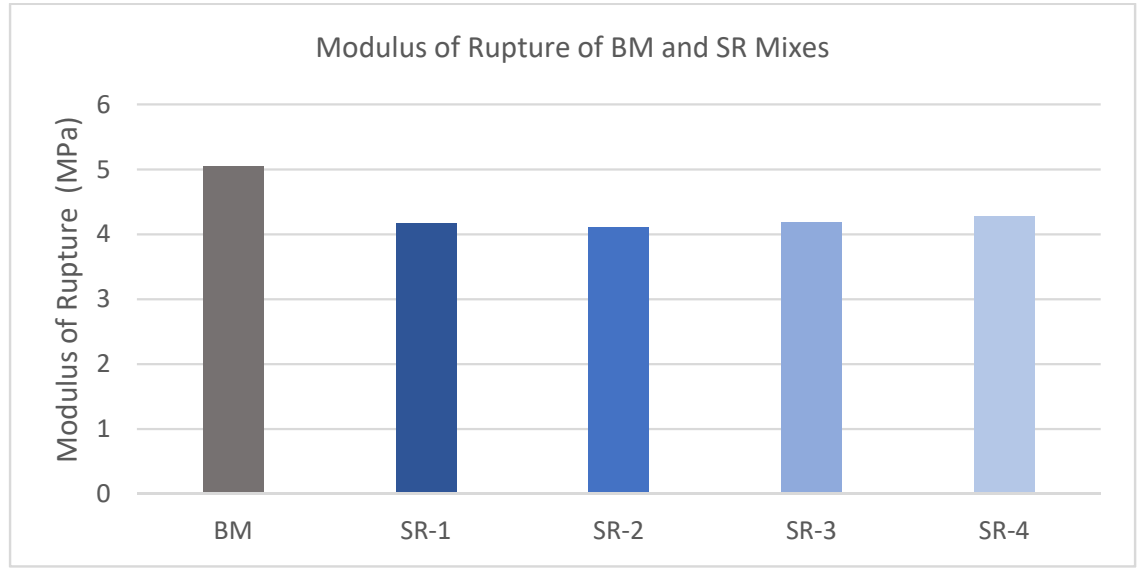

(a)

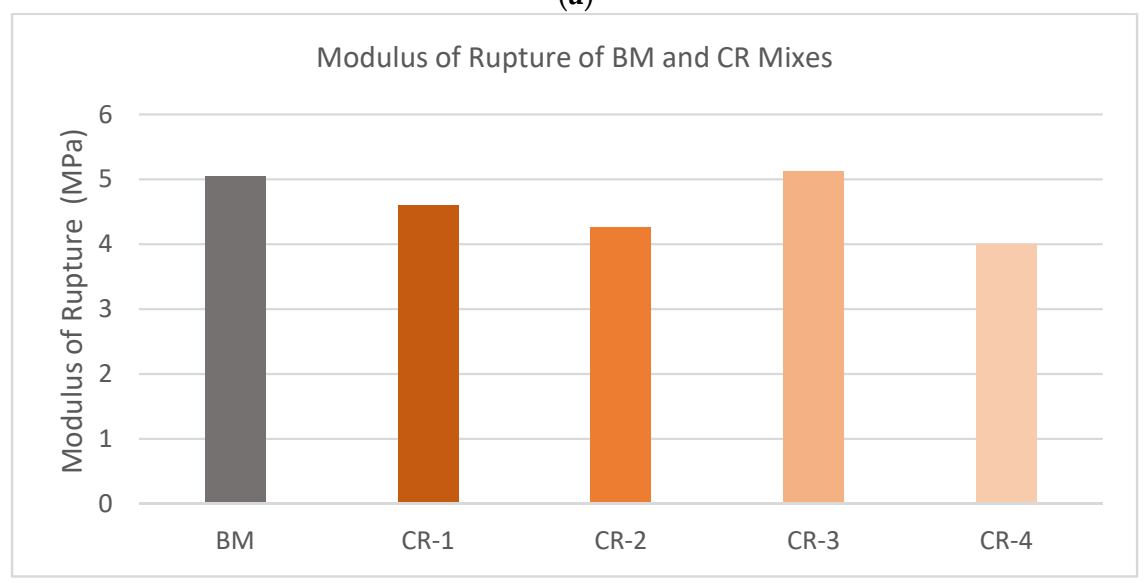

(b)

Figure 11. Cont. 


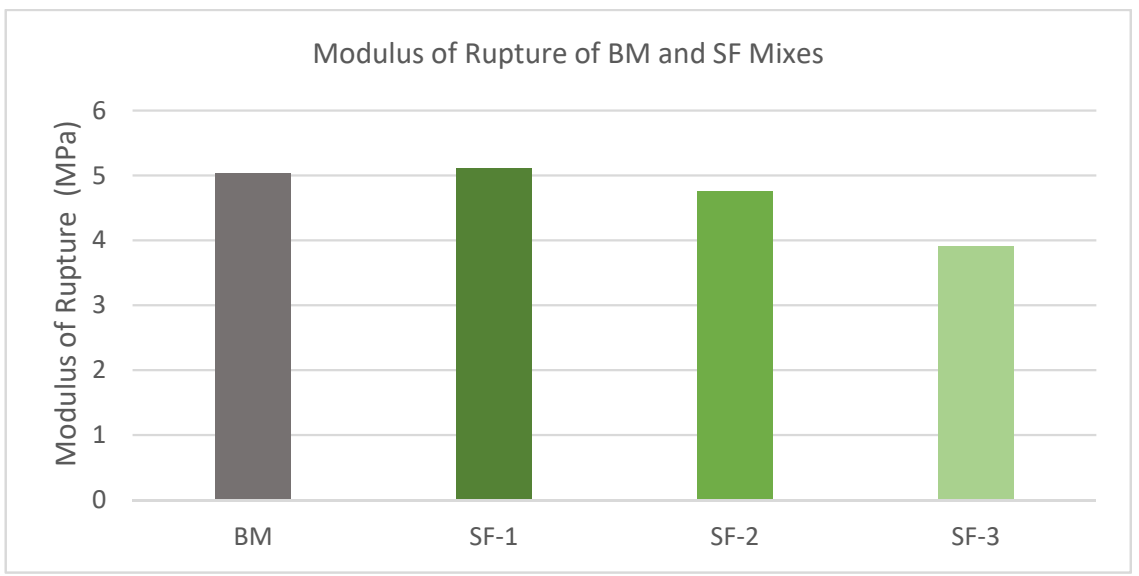

(c)

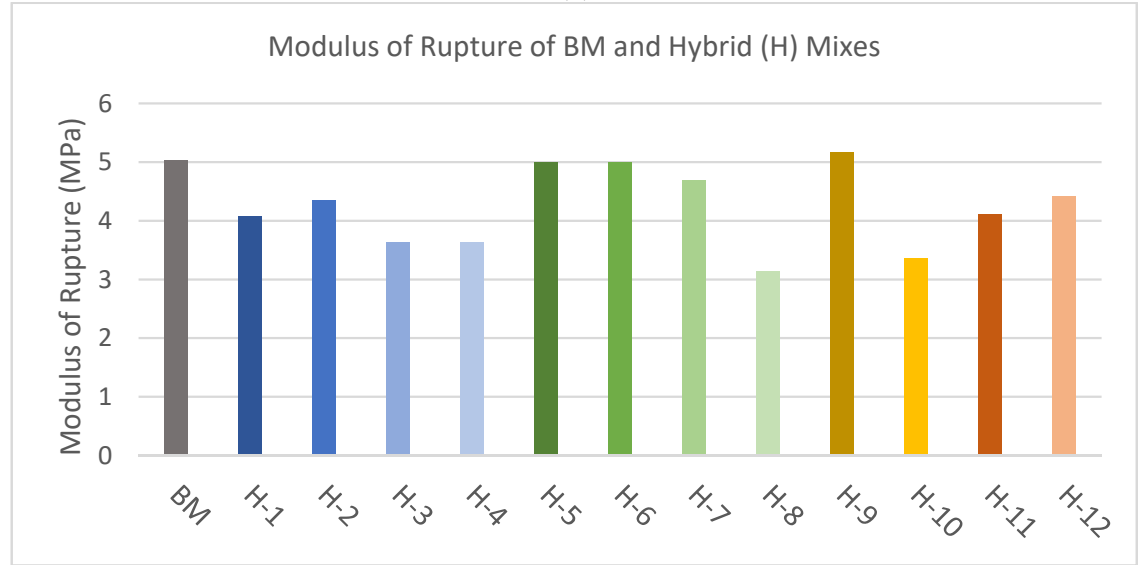

(d)

Figure 11. Comparing the modulus of rupture of the benchmark mix (5.04 MPa) with (a) SR; (b) CR; (c) SF; and (d) Hybrid (i.e., H) mixes.

\section{Discussion}

\subsection{Slump Test}

Figure 6a,c show the slump test results for mixes containing SR and SF, respectively. The results shown in the figures are inconclusive, as they do not clearly indicate a trend with the introduction of either of the materials. However, the reduction in slump due to the incorporation of SF into the concrete mix was corroborated by findings by other researchers [33]. Additionally, all SR and SF mixes presented acceptable slump values that are within the target slump range for pavements $(70 \mathrm{~mm} \pm 30 \mathrm{~mm})$.

Figure $6 \mathrm{~b}$ shows the slump test results for mixes containing $\mathrm{CR}$. As shown in the figure, the introduction of CR initially decreased the slump but then increases with additional doses. This trend is the case for doses up to and including 15\%. The introduction of $20 \%$ $\mathrm{CR}$ reverses the trend but still maintains a slump value similar to the benchmark. The conclusions of this family of concrete are similar to that of other researchers [34].

Figure $6 \mathrm{~d}$ shows the slump test results for the hybrid mixes, containing combinations of SR, CR, and SF. The figure shows four "families" of hybrid mixes: combinations of SR and $\mathrm{SF}$ are shown in red, combinations of $\mathrm{CR}$ and SF are shown in blue, combinations of $\mathrm{SR}, \mathrm{CR}$, and $\mathrm{SF}$ are shown in yellow, and combinations of $\mathrm{SR}$ and $\mathrm{CR}$ are shown in green. The results in red show that with the exception of $\mathrm{H} 2$, there is a clear and increasing trend in the slump of concrete. Initially, the slump significantly decreased but then increases, with the last mix reaching the benchmark's slump. The results in blue show that the slump remained somewhat consistent, hovering in the range of $85-100 \mathrm{~mm}$. This excludes the results of $\mathrm{H} 8$, which can be considered anomalous. The results in yellow show that there is a slight increase in the slump at the higher dosage of H10, but this remains significantly 
lower than the benchmark's slump. The results in green show that there is a slight increase in the slump at the higher dosage of H12, but this remains lower than the benchmark's slump and outperforms the results in yellow. All slump test results were within the target slump range for pavements.

\subsection{Compressive Strength}

Figure 8a shows the variation of compressive strength of samples containing SR compared with the benchmark at the 7- and 28-day marks. As shown in the figure, compressive strength is directly affected by the introduction of SR into the mix, where larger quantities of SR present in the mix lead to a decrease in the 7- and 28-day compressive strength in an almost proportional fashion. The samples also exhibit similar rates of compressive strength gain to the benchmark mix, as shown by the slope of the lines. Comparable studies stated that the introduction of SR would reduce the compressive strength by up to $23 \%[27,29]$, where the compressive strength reduction in the results of this study ranged between 13\% and $36 \%$. There is some correlation between the results of the study and existing literature, with variations in the upper/lower bounds of compressive strength reduction. However, the results stand in contrast to the findings of some other researchers [13] who found that compressive strength, among other properties, was improved by the introduction of SR into the mix.

Figure $8 \mathrm{~b}$ shows the variation of compressive strength of samples containing CR compared with the benchmark at the 7- and 28-day marks. As shown in the figure, there is no clear correlation between the amount of CR present in the sample and the compressive strength at any age. However, the introduction of CR lowers both 7- and 28day compressive strength. It is worth mentioning that all concrete mixes in this figure have acceptable 28-day compressive strengths, ranging from 26.4 $\mathrm{MPa}$ (for CR4) to $31.1 \mathrm{MPa}$ (for CR2). Comparable studies stated that the introduction of $\mathrm{CR}$ would reduce the compressive strength by $15 \%$ [26], where the compressive strength reduction in the results of this study ranged between $8 \%$ and $30 \%$. It is worth mentioning that the replacements considered in this study are within the bounds of acceptable replacement of conventional materials [29].

Figure $8 \mathrm{c}$ shows the variation of compressive strength of samples containing SF compared with the benchmark at the 7- and 28-day marks. As shown in the figure, an interesting observation occurs at SF2, where the 7-day compressive strength was higher than the benchmark and the 28-day compressive strength was very similar to the benchmark. Other than that, both SF1 and SF3 performed similarly to each other, both being slightly lower than the benchmark and having similar rates of compressive strength gain to each other. This comes at odds with the conclusions of other researchers who had success in increasing mechanical properties (such as compressive strength) with increasing dosages of SF [30].

Figure 9a shows the variation of compressive strength of samples containing a combination of SR and SF compared with the benchmark at the 7- and 28-day marks. As shown in the figure, higher doses of SR with the introduction of $0.1 \%$ SF into the mix decrease the 7and 28-day compressive strength. However, there is no impact on the rate of compressive strength gain in any of the samples, exhibiting similar slopes to that of the benchmark.

Figure $9 \mathrm{~b}$ shows the variation of compressive strength of samples containing a combination of CR and SF compared with the benchmark at the 7- and 28-day marks, and Figure $9 \mathrm{c}$ shows the variation of compressive strength of samples containing a combination of SR, CR, and SF compared with the benchmark at the 7- and 28-day marks. An interesting observation can be seen across the two figures above, where the compressive strengths of the samples converge to the same value at the 28-day mark. The rate of compressive strength gain is expected to decrease as the proportion of the replacement materials increase in the mixes.

All mixes used in this study exhibit acceptable levels of 28-day compressive strength, with a minimum of $21.3 \mathrm{MPa}(\mathrm{H}-4)$ and a maximum of $33.1 \mathrm{MPa}(\mathrm{SF}-2)$. 


\subsection{Tensile Strength}

Figure 10a shows the variation of split tensile strength of samples containing SR compared with the benchmark. The results show a very clear decreasing trend as the percentage of SR increases in the mix. The results of SR3 can be considered anomalous.

Figure 10b shows the variation of split tensile strength of samples containing CR compared with the benchmark. The results show a very clear decreasing trend as the percentage of CR increases in the mix. Comparable studies stated that the introduction of $\mathrm{CR}$ would reduce the tensile strength by up to $43 \%$ [2,26], where the tensile strength reduction in the results of this study ranged around $22 \%$. While this is a marked improvement over existing literature, it still represents a significant drop in the tensile strength of concrete.

Figure 10c shows the variation of split tensile strength of samples containing SF compared with the benchmark. The results show very consistent tensile strength results that are close to the benchmark's results, regardless of the dosage of SF present in the concrete. The results of this test indicate that there is no advantage in incorporating additional doses of steel fibers beyond $0.1 \%$. This, coupled with the fact that higher dosages of SF led to a significant decrease in the slump, justifies the use of this dosage in the hybrid mixes.

Figure 10d shows the tensile strength test results for the hybrid mixes, containing combinations of SR, CR, and SF. The figure shows four "families" of hybrid mixes: combinations of SR and SF are shown in shades of green, combinations of CR and SF are shown in shades of orange, combinations of SR, CR, and SF are shown in shades of blue, and combinations of SR and CR are shown in shades of yellow. The results in green show that there is a clear decreasing trend in the tensile strength of the samples as the proportion of SR increases in the samples. The results in orange indicate a clear trendline showing that the values are almost consistent throughout the samples tested. However, the samples have tensile strength values that are lower than the benchmark's. The results in blue show that there is a slight increase in the tensile strength at the higher dosage of H10. The results in yellow show that there is a slight decrease in the tensile strength at the higher dosage of $\mathrm{H} 12$.

\subsection{Modulus of Rupture}

Figure 11a shows the variation of modulus of rupture of samples containing SR compared with the benchmark. The results show a very clear trend where the modulus of rupture remains consistent for all four dosages of SR tested.

Figure $11 \mathrm{~b}$ shows the variation of modulus of rupture of samples containing CR compared with the benchmark. The results show a very clear trend where the modulus of rupture decreases with increasing dosages of crumb rubber. The results of CR3 can be considered anomalous. The findings of the CR trials match closely with the findings of other researchers, who have stated that the incorporation of rubber products has a negative effect on mechanical properties [2].

Figure 11c shows the variation of modulus of rupture of samples containing SF compared with the benchmark. Initially, this does not have an impact on the modulus of rupture at a low dosage. However, with increasing dosages of SF, there is a clear trend of decreasing modulus of rupture. As was the case with the tensile test results, the results of this test also indicate that there is no advantage in incorporating additional doses of steel fibers beyond $0.1 \%$. Again, this comes at odds with the conclusions of other researchers who had success in increasing mechanical properties (such as flexural strength) with increasing dosages of SF [30].

Figure $11 \mathrm{~d}$ shows the test results for the modulus of rupture for the hybrid mixes, containing combinations of SR, CR, and SF. The figure shows four "families" of hybrid mixes: combinations of SR and SF are shown in shades of blue, combinations of CR and $\mathrm{SF}$ are shown in shades of green, combinations of SR, CR, and SF are shown in shades of yellow, and combinations of SR and CR are shown in shades of orange. The results in blue show that there is a clear decreasing trend in the modulus of rupture of the samples as the 
proportion of SR increases in the samples. The results in green show that there is a clear decreasing trend in the modulus of rupture of the samples as the proportion of CR increases in the samples. However, results up to and including $\mathrm{H} 7$ are very close to the modulus of rupture of the benchmark, which is similar to the findings of other researchers [2,35]. The results in yellow show that there is a sharp drop in the modulus of rupture values as the dosage of replacement materials increases, while noting the improvement in the modulus of rupture for $\mathrm{H}-9$ compared with the benchmark mix, which proves the benefits of including all replacement materials in the concrete mix. The results in orange show that there is a sharp increase in the modulus of rupture values as the dosage of replacement materials increases.

\section{Conclusions}

After analyzing the results presented above, and despite the reduction in fresh properties due to the introduction of recycled tire products in the concrete mix, it has been shown that multiple tire by-products (shredded/crumb rubber and recovered steel fibers) can be successfully hybridized to produce a novel pavement-grade green concrete that is suited for use in hot-weather climates. This is important, as it achieves two goals in one: to be able to produce a sustainable construction material that is tailored for use in Kuwait's climate and to also reduce the number of tires going to landfill.

- The incorporation of CR has a detrimental effect on all concrete properties considered in this study. However, the effects on tensile strength and modulus of rupture were the most evident.

- The introduction of SR into a benchmark concrete mix has a noticeable, almost proportional effect on the 7 and 28-day compressive strength and tensile strength.

- The introduction of $0.1 \%$ and $0.2 \%$ SF managed to increase the modulus of rupture and the 7-day compressive strength of the benchmark, respectively. On the other hand, excessive use of SF leads to the concrete having significantly weaker properties compared to a benchmark mix.

- The preliminary results from the individual tire products were used to determine optimal dosages of each material for use in a hybrid mix, which has not been attempted by many researchers. It is interesting to note how the hybrid mixes exhibit very similar trends to their constituent replacement materials. The incorporation of each material at a low dosage ( $5 \%$ for rubber products and $0.1 \%$ for steel fibers) was able to maintain the properties of the benchmark mix, if not improve on them.

All mixes, whether individual replacement or hybrid mixes, exhibited acceptable properties for pavement-grade concrete for use in hot climates. The conclusions of this study show that it is possible to hybridize all materials sourced from recycled tires in the production of a feasible pavement-grade concrete suited for hot weather. Possible extensions of the project could include the investigation of other properties to evaluate the usefulness of the hybrid concrete, such as measuring skid resistance and modulus of elasticity. Further, long-term effects of using this concrete could be modeled using finite-element analysis software packages, which could be used to predict the behavior of the concrete while it is being used at a selected intersection in Kuwait.

Author Contributions: Conceptualization, S.M.S., A.R.A., A.J., N.M. and A.F.; methodology, S.M.S.; formal analysis, S.M.S., A.R.A., A.J. and N.M.; investigation, A.R.A., A.J. and N.M.; resources, A.R.A.; data curation, A.J.; writing-original draft preparation, S.M.S., A.R.A., A.J., N.M. and A.F.; writingreview and editing, S.M.S., A.R.A., A.J., N.M. and A.F.; supervision, S.M.S.; project administration, A.F.; funding acquisition, S.M.S. All authors have read and agreed to the published version of the manuscript.

Funding: This project was funded "partially" by Kuwait Foundation for the Advancement of Sciences under project code: PR19-15EV-02.

Institutional Review Board Statement: Not applicable. 
Informed Consent Statement: Not applicable.

Data Availability Statement: The data presented in this study are available on request from the corresponding author.

Acknowledgments: The authors would like to acknowledge Tahir Afrasiab for his contributions, hard work and dedication while preparing the concrete mixes for this study. The authors would like to thank Sameer Hamoush of North Carolina A\&T State University for his input and advice throughout the course of the project. The authors would also like to express their gratitude to Green Rubber Recycling Co. for providing samples of their recycled tire products to be used in this study. The authors are grateful to Sika for providing the team with the superplasticizer used in the study.

Conflicts of Interest: The authors declare no conflict of interest.

$\begin{array}{ll}\text { Abbreviations } \\ \mathrm{CR} & \text { crumb rubber } \\ \mathrm{Kg} & \text { kilogram } \\ \mathrm{Mm} & \text { millimeter } \\ \mathrm{MPa} & \text { megapascal } \\ \mathrm{m}^{3} & \text { cubic meter } \\ \mathrm{SF} & \text { steel fiber } \\ \mathrm{SR} & \text { shredded rubber }\end{array}$

\section{References}

1. Arab Times. Available online: https://www.arabtimesonline.com/news/red-tape-proper-planning-dearth-delays-shifting-ofhuge-tire-dump/ (accessed on 1 January 2021).

2. Meddah, A.; Miloud, B.; Bali, A. Use of shredded rubber tire aggregates for roller compacted concrete pavement. J. Clean. Prod. 2014, 72, 187-192. [CrossRef]

3. Kuwait News Agency. Available online: https://www.kuna.net.kw/ArticleDetails.aspx?id=2931763\&language=en (accessed on 1 January 2021).

4. Arab Times. Available online: https://www.arabtimesonline.com/news/millions-of-tires-destroyed-in-fire/ (accessed on 1 January 2021).

5. Kuwait News Agency. Available online: https://www.kuna.net.kw / ArticleDetails.aspx?id=2367062\&Language=en (accessed on 1 January 2021).

6. Kuwait News Agency. Available online: https://www.kuna.net.kw/ArticleDetails.aspx?id=2234353\&Language=en (accessed on 1 January 2021).

7. Fazli, A.; Rodrigue, D. Waste Rubber Recycling: A Review on the Evolution and Properties of Thermoplastic Elastomers. Materials 2020, 13, 782. [CrossRef] [PubMed]

8. Debrah, J.K.; Vidal, D.G.; Dinis, M.A.P. Raising Awareness on Solid Waste Management through Formal Education for Sustainability: A Developing Countries Evidence Review. Recycling 2021, 6, 6. [CrossRef]

9. Kassim, S.M. The Importance of Recycling in Solid Waste Management. Macro. Symp. 2012, 320, 34-50. [CrossRef]

10. Assadi, M.H.N.; Sahajwalla, V. Recycling End-of-Life Polycarbonate in Steelmaking: Ab Initio Study of Carbon Dissolution in Molten Iron. Ind. Eng. Chem. Res. 2014, 53, 3861-3864. [CrossRef]

11. Yazdi, M.A.; Yang, J.; Yihui, L.; Su, H. A Review on Application of Waste Tire in Concrete. Int. Sch. Sci. Res. Innov. 2015, 9, 1656-1661.

12. Toghroli, A.; Shariati, M.; Sajedi, F.; Ibrahim, Z.; Koting, S.; Mohamad, E.T.; Khorami, M. A review on pavement porous concrete using recycled waste materials. Smart Struct. Syst. 2018, 22, 433-440.

13. Lavagna, L.; Nisticò, R.; Sarasso, M.; Pavese, M. An Analytical Mini-Review on the Compression Strength of Rubberized Concrete as a Function of the Amount of Recycled Tires Crumb Rubber. Materials 2020, 13, 1234. [CrossRef] [PubMed]

14. Forrest, M.J. Recycling and Re-Use of Waste Rubber, 2nd ed.; De Gruyter: Berlin, Germany, 2019; pp. 1-20.

15. Bulei, C.; Todor, M.P.; Heput, T.; Kiss, I. Directions for material recovery of used tires and their use in the production of new products intended for the industry of civil construction and pavements. IOP Conf. Ser. Mater. Sci. Eng. 2018, 294, 012064. [CrossRef]

16. Oliveira Neto, G.C.d.; Chaves, L.E.C.; Pinto, L.F.R.; Santana, J.C.C.; Amorim, M.P.C.; Rodrigues, M.J.F. Economic, Environmental and Social Benefits of Adoption of Pyrolysis Process of Tires: A Feasible and Ecofriendly Mode to Reduce the Impacts of Scrap Tires in Brazil. Sustainability 2019, 11, 2076. [CrossRef]

17. Al-Fakih, A.; Mohammed, B.S.; Liew, M.S. Tires Rubber as a Useable Material in Civil Engineering Applications: An Overview. Int. J. Adv. Res. Eng. Technol. 2020, 11, 315-325. 
18. Senin, M.S.; Shahidan, S.; Abdullah, S.R.; Guntor, N.A.; Leman, A.S. A review on the suitability of rubberized concrete for concrete bridge decks. IOP Conf. Ser. Mater. Sci. Eng. 2017, 271, 012074. [CrossRef]

19. Hejna, A.; Zedler, Ł.; Przybysz-Romatowska, M.; Cañavate, J.; Colom, X.; Formela, K. Reclaimed Rubber/Poly( $\varepsilon$-caprolactone) Blends: Structure, Mechanical, and Thermal Properties. Polymers 2020, 12, 1204. [CrossRef]

20. Alfayez, S.; Suleiman, A.R.; Nehdi, M.L. Recycling Tire Rubber in Asphalt Pavements: State of the Art. Sustainability 2020, 12, 9076. [CrossRef]

21. Aiello, M.A.; Leuzzi, F. Waste tyre rubberized concrete: Properties at fresh and hardened state. Waste Manag. 2010, 30, 1696-1704. [CrossRef] [PubMed]

22. Gupta, T.; Chaudhary, S.; Sharma, R.K. Mechanical and durability properties of waste rubber fiber concrete with and without silica fume. J. Clean. Prod. 2016, 112, 702-711. [CrossRef]

23. Obinna, O.; Panesar, D.K. Hardened properties of concrete mixtures containing pre-coated crumb rubber and silica fume. J. Clean. Prod. 2014, 82, 125-131.

24. Guneyisi, E.; Gesoglu, M.; Ozturan, T. Properties of rubberized concretes containing silica fume. Cem. Concr. Res. 2004, 34, 2309-2317. [CrossRef]

25. Kanmalai Williams, C.; Partheeban, P. Experimental investigation on recycled rubber filled concrete. Int. J. Earth Sci. Eng. 2016, 9 , 170-175.

26. Khan, S.; Singh, A. Behavior of Crumb Rubber Concrete. Int. J. Res. Eng. 2018, 8, 86-92.

27. Sofi, A. Effect of Waste Tyre Rubber on Mechanical and Durability Properties of Concrete-A review. Ain Shams Eng. J. 2018, 9 , 2691-2700. [CrossRef]

28. Akinwonmi, A.S.; Seckley, E. Mechanical Strength of Concrete with Crumb and Shredded Tyre As Aggregate Replacement. Int. J. Eng. Res. Appl. 2013, 3, 1098-1101.

29. Issa, C.A.; Salem, G. Utilization of Recycled Crumb Rubber as Fine Aggregates in Concrete Mix Design. Constr. Build. Mater. 2013, 42, 48-52. [CrossRef]

30. Irmawaty, R.; Parung, H.; Abdurrahman, M.A.; Nur Qalbi, I. Flexural toughness of concrete with aggregate substitution (steel fiber, crumb rubber and tire chips). IOP Conf. Ser. Earth Environ. Sci. 2020, 419, 012038. [CrossRef]

31. Chen, Y.; Liang, X.; Liang, L. Application research of steel fiber rubber regenerated concrete engineering. IOP Conf. Ser. Earth Environ. Sci. 2020, 526, 012087. [CrossRef]

32. Gul, S.; Nasser, S. Concrete Containing Recycled Rubber Steel Fiber. Procedia Struct. Integr. 2019, 18, 101-107. [CrossRef]

33. Samarakoon, S.M.S.M.K.; Ruben, P.; Pedersen, J.W.; Evangelista, L. Mechanical Performance of Concrete Made of Steel Fibers from Tire Waste. Case Stud. Constr. Mater. 2019, 11, e00259. [CrossRef]

34. Noaman, A.; Abu Bakar, B.H.; Akil, H.M. Investigation on the mechanical properties of rubberized steel fiber concrete. Eng. Struct. Technol. 2017, 9, 79-92. [CrossRef]

35. Eisa, A.S.; Elshazli, M.T.; Nawar, M.T. Experimental investigation on the effect of using crumb rubber and steel fibers on the structural behavior of reinforced concrete beams. Constr. Build. Mater. 2020, 252, 119078. [CrossRef]

36. Mohammad, B.M.; Adamu, M.; Shafiq, N. A review on the effect of crumb rubber on the properties of rubbercrete. Int. J. Civ. Eng. Technol. 2017, 8, 599-617.

37. Hot Weather Concrete-American Concrete Institute. Available online: https://www.concrete.org/topicsinconcrete/topicdetail/ hot $\% 20$ weather\%20concrete? search=hot $\% 20$ weather\%20concrete (accessed on 29 January 2021).

38. ASTM C617/C617M-15. Standard Practice for Capping Cylindrical Concrete Specimens; ASTM International: West Conshohocken, PA, USA, 2015. Available online: www.astm.org (accessed on 3 February 2021).

39. ASTM C496/C496M-17. Standard Test Method for Splitting Tensile Strength of Cylindrical Concrete Specimens; ASTM International: West Conshohocken, PA, USA, 2017. Available online: www.astm.org (accessed on 3 February 2021).

40. ASTM C39/C39M-20. Standard Test Method for Compressive Strength of Cylindrical Concrete Specimens; ASTM International: West Conshohocken, PA, USA, 2020. Available online: www.astm.org (accessed on 3 February 2021).

41. ASTM C78/C78M-18. Standard Test Method for Flexural Strength of Concrete (Using Simple Beam with Third-Point Loading); ASTM International: West Conshohocken, PA, USA, 2018. Available online: www.astm.org (accessed on 3 February 2021). 